\title{
INTERthesis
}

\section{A INTERSUBJETIVIDADE EM MERLEAU-PONTY E NO CONSTRUCIONISMO SOCIAL ALGUMAS CONSIDERAÇÕES}

\section{Resumo:}

Marcelo Naputano ${ }^{1}$

Elvira Cicognani ${ }^{2}$

O objetivo central de nosso texto é compreendermos a construção da intersubjetividade em Merleau-Ponty, do sujeito na relação com o outro em suas construções existenciais e fazermos a mesma reflexão sobre a concepção do estabelecimento da intersubjetividade na teoria do Construcionismo Social, na possibilidade de um diálogo, sem, contudo, a pressuposição de uma conclusão de acepção moral de atribuição de maior valor a uma teoria em detrimento da outra. Para tanto, iniciamos com algumas breves considerações sobre os afetos e desafetos históricos entre filosofia e psicologia para, posteriormente, delinearmos melhor nosso ponto central em Merleau-Ponty e no Construcionismo Social, desenvolvendo os possíveis significados da intersubjetividade nestes. É interessante notarmos que, apesar da distância no tempo e da construção teórica entre MerleauPonty e o Construcionismo Social, podemos verificar uma similaridade na busca de uma solução ao problema sujeito-objeto transcendendo a esta polarização nas considerações sobre a intersubjetividade mesmo que com propostas divergentes.

Palavras-chave: Intersubjetividade. Merleau-Ponty. Construcionismo Social.

\section{MERLEAU-PONTY E A INTERSUBJETIVIDADE}

Inicialmente, para refletirmos a respeito das contribuições de Merleau-Ponty para a construção da intersubjetividade e, posteriormente, refletirmos sobre as concepções da construção da intersubjetividade no Construcionismo Social, se faz necessário rememorarmos a importância do diálogo e dos embates entre a filosofia e a psicologia, verdadeira relação de amor e ódio que historicamente marca estes dois campos do conhecimento humano.

Se, por um lado, a psicologia tem seu nascimento na evidente tentativa de se livrar de suas raízes filosóficas para sua autonomia, de outro lado, sempre se baseou em fontes e temas filosóficos: "todos os grandes sistemas filosóficos desde a

\footnotetext{
1 Doutorando no Programa de Psicologia e Sociedade da Universidade Estadual Paulista Júlio de Mesquita Filho, Assis, São Paulo, Brasil. Doutorado sanduíche na Facoltà di Psicologia dell'Università di Bologna, Itália. E-mail: naputano@libero.it

2 Doutora em Psicologia pela Universidade de Padova, Itália. Professora efetiva e membro no colégio de docentes no programa de doutorado na Facoltà di Psicologia dell'Università di Bologna, Coordenadora do centro de pesquisa Centro per l'Empowerment delle Scuole, delle Organizzazioni e della Comunità da Universidade de Bolonha, Itália. E-mail: elvira.cicognani@unibo.it
} 
Antiguidade incluem noções e conceitos relacionados ao que hoje faz parte do domínio da psicologia científica" (FIGUEIREDO, 2004, p.14). A tentativa desta "autonomia", ironicamente baseada na filosofia cartesiana, que é em parte a característica ainda hoje de algumas psicologias, é muito bem descrita por Foulquié, quando diz: "A filosofia moderna remonta a Descartes; e como a Psicologia era, e continua em larga medida, o apanágio dos filósofos, recebeu do cartesianismo princípios dos quais, até agora, não se desembaraçou completamente" (FOULQUIÉ, 1965, p.1).

Merleau-Ponty se insere nesta discussão de modo muito particular, pois foi um filósofo que acabou ocupando inesperadamente a cadeira de Psicologia e Pedagogia da Criança a convite da Universidade de Paris-Sorbonne que, segundo Coelho \& Carmo, muito influenciou a obra deste autor:

\begin{abstract}
Nomeado para uma cadeira (Psicologia e Pedagogia da Criança) que não correspondia a seus gostos e vocação, Merleau-Ponty se fez, durante alguns anos, psicólogo e pedagogo, sem abandonar, no entanto, seu olhar crítico de filósofo. O fato é que, com este contato "forçado", com a psicologia, Merleau-Ponty descobrirá possibilidades novas para o seu questionamento filosófico, o que pode ser comprovado pela influência exercida pela psicanálise (que até então, ele pouco conhecia) em seus textos publicados na década de 1950 (COELHO JÚNIOR; CARMO, 1991, p. 33).
\end{abstract}

Apesar da discutível afirmação de Coelho Júnior \& Carmo de que MerleauPonty pouco conhecia as obras da psicanálise, é de fato no inicio da década de 1950 que Merleau-Ponty vai iniciar a dialogar com estas obras com maior profundidade, por exemplo, na publicação de L'institution/La passivité: notes de cours au Collége de France de 1954-1955 (MERLEAU-PONTY, 2003).

A despeito disso, é interessante notarmos de que maneira a experiência existencial, acima citada, coloca em evidência a história de um filósofo que, de certo modo, vai se transformando também em psicólogo em um momento histórico no qual estas duas disciplinas se questionavam mutuamente. É interessante a afirmação de Merleau-Ponty que, incidindo reconhecimento da biografia na obra de uma pessoa, afirma, anteriormente ao convite para a Universidade de Paris: "É certo que a vida não explica a obra, porém certo é também que se comunicam. A verdade é que essa obra por fazer exigia essa vida" (MERLEAU-PONTY, 2004, p. 135-136).

Não é nosso interesse, neste texto, abordarmos as questões da polarização entre o conhecimento científico, que a psicologia da época buscava em 
contraposição ao conhecimento metafísico, mesmo porque Merleau-Ponty procura uma reflexão que possa considerar estas questões, embora mudando o foco da necessidade de uma rivalidade:

Entre o conhecimento científico e o saber metafísico não pode haver rivalidade. Uma ciência sem filosofia não saberia, literalmente, do que fala. Uma filosofia sem exploração metódica dos fenômenos chegaria apenas a verdades formais, isto é, a $\operatorname{erros}^{3}$ (MERLEAU-PONTY, 1996, p. 120).

O que nos interessa especificamente em Merleau-Ponty é a sua atitude intelectual frente a polaridades ou dicotomias do subjetivismo ou do objetivismo sem a necessidade de uma síntese final.

Não há busca de uma nova síntese que conciliasse os opostos definitivamente, mas sim a certeza de que é na dinâmica entre polaridades que se pode ser encontrado o fundamento para um pensar consistente, acima de tudo, em saber circunscrever um campo a ser pensado (COELHO JÚNIOR; CARMO, 1991, p. 16).

Por esta característica de pensar a ambiguidade, questionando a noção de causalidade na rejeição da origem das coisas como sinônimo de entendimento das mesmas, de conjecturar por meio de grande número de temáticas, interrogando-se a cada novo fenômeno, é que podemos considerar Merleau-Ponty um autor de uma atualidade impressionante. Um autor quase "pós-moderno", no sentido de que não busca uma verdade absoluta de síntese e associa, sem sujeições, a consciência e a natureza orgânica ao social.

Certamente que a noção de estrutura não é sinônimo de ciência pósmoderna, mas, dadas as devidas diferenças dos contextos da formação do pensamento de Merleau-Ponty e dos paradigmas das ciências pós-modernas, na proposta de Boaventura de Souza Santos, Merleau-Ponty é seguramente um inovador de perspectivas, inclusive em suas críticas feitas à Psicologia da Forma da época por meio de sua reiterada proposta de que a experiência, é experiência vivida. Para afirmarmos, nos moldes da ciência pós-moderna: "Todo conhecimento é autoconhecimento" (SANTOS, 1988, p. 66), é necessário compreender que a ontologia proposta por Merleau-Ponty é uma tentativa de pensar a relação sujeito e objeto de modo distinto da clássica separação.

Merleau-Ponty opera segundo o registro de uma intenção ontológica distinta

${ }^{3}$ Original: "Tra conoscenza scientifica e sapere metafisico, che la rimette sempre in presenza del suo compito, non può esserci rivalità. Una scienza senza filosofia non saprebbe, alla lettera, di che cosa essa parli. Una filosofia senza esplorazione metodica dei fenomeni darebbe solo luogo a verità formali, cioè ad error". Trad. Marcelo Naputano

R. Inter. Interdisc. INTERthesis, Florianópolis, v.13, n.2, p.19-37, Mai-Ago. 2016 
da ontologia clássica, que perpetua a cisão entre sujeito e objeto. É preciso reconhecer, todavia, que Merleau-Ponty, à época da Fenomenologia da percepção, ainda não contava com instrumentos teóricos que lhe permitissem ultrapassar verdadeiramente o intelectualismo, conforme observa Bimbenet (VERÍSSIMO, 2012, p. 369).

Mas estes bons motivos, para nos debruçarmos hoje sobre Merleau-Ponty, são os motivos também da dificuldade de entendimento de sua obra:

Desde o início, portanto, coloca-se a dificuldade de escrever sobre a vida e a obra de um filósofo que denuncia a todo momento os enganos da expressão. Filósofo da existência, do corpo, fenomenólogo da percepção, Merleau-Ponty nos instiga a todo instante, impedindo um pensamento cristalizado que se reduza, seja à explicação, seja à devoção (COELHO JÚNIOR; CARMO, 1991, p. 12-13).

Deste modo, redimensionados em função da complexidade deste autor, propomos abordar a intersubjetividade em Merleau-Ponty, fazendo um corte preciso de interesse, mas que, nem por isto, faz de nossa empresa algo mais simples. Este redimensionamento se institui e nos remete em nossas considerações a um dos conceitos centrais de sua obra, que é o da experiência vivida anterior à reflexão fundamentada no ato da percepção e que é a expressão maior da relação de nosso corpo no mundo, ou melhor, de nosso corpo-mundo. Mais especificamente ainda, nossa preocupação será a de fazermos algumas considerações sobre este corpomundo na relação com o outro, denominado intersubjetividade, que, segundo Verissimo (2012), nos remete necessariamente aos trabalhos posteriores à Fenomenologia da percepção.

Nos trabalhos posteriores à Fenomenologia da percepção, o problema da intersubjetividade adquire grande importância para Merleau-Ponty. É nesse panorama que o autor recorre à noção de esquema corporal. Essa mobilização conceitual ocorre em seus cursos da Sorbonne dedicados à psicologia da criança. Com efeito, nesse contexto, ela recebe um tratamento que a eleva a um papel central na ontologia merleau-pontiana (VERISSIMO, 2012, p. 370).

Na progressão de sua obra, Merleau-Ponty, reforçando sua contraposição às concepções cartesianas da separação entre sujeito e objeto, vai melhor estendendo as possibilidades da percepção na descrição do sujeito que percebe e é percebido e, obviamente, este elemento vai inserir a necessidade da compreensão do mundo das coisas e das relações, relações com o outro:

O estudo da percepção sofre, não obstante, uma importante metamorfose ao se tornar investigação acerca do sensível. Doravante, trata-se de atribuir ao corpo não apenas o caráter de sujeito da percepção, mas também de ente percebido, ente sensível, na amplitude polissêmica do termo [...] (VERISSIMO,, 2012, p. 370).

R. Inter. Interdisc. INTERthesis, Florianópolis, v.13, n.2, p.19-37, Mai-Ago. 2016 
A compreensão entre o "eu" e o "outro/outros" é o resultado de nossas interações no mundo. As nossas ações no mundo se encontram com as ações do outro/outros e descobrem seu entendimento entre as diversas intenções de cada um. A própria presença do outro/outros é um fenômeno para o "eu". Claro que a afirmação desta intencionalidade é uma negação do conceito mecanicista da psicologia behaviorista que Merleau-Ponty sempre questionou, pois o homem não se reduz a seus fatores biológicos em interação com o ambiente, em relações de causa e efeito. A dificuldade conceitual aqui, no entanto, é precisamente aquela de compreendermos uma consciência que por fim se resolve também na consciência do outro. Mesmo que as consciências sejam reconhecidas como fenômenos existenciais individuais, o outro (outros) coloca em questão o quanto eu sou sujeito singular na percepção do mundo. Afinal, o mundo é uma construção da minha percepção ou a construção social na qual minha percepção está inserida e condicionada? O reconhecimento do outro é um ato de consciência, porquanto defendia Husserl, ou de percepção corporal ou a que é devido?

Merleau-Ponty vai construir uma possibilidade, em uma nova definição do que é ser consciência, afirmando que: "Ser uma consciência, ou, antes, ser uma experiência, é comunicar-se interiormente com o mundo, com o corpo e com os outros, ser com eles em lugar de estar ao lado deles" (MERLEAU-PONTY, 1999, p.142). Tal conceito se baseia na ideia de uma encarnação não resultante de uma transcendência fora do corpo através do outro na construção da intersubjetividade; ou seja, dito de outro modo, de uma transcendência que não é fora do mundo, mas encarnada nele - o que Merleau-Ponty vai chamar cogito4.

Eis o porquê da importância dada por Merleau-Ponty ao corpo, corpo fenomênico que me joga no mundo para uma experiência na descoberta do outro a partir de minha própria existência e, com o mesmo processo, dos outros em relação à minha existência. Não é a relação entre sujeito-objeto que constitui a intersubjetividade e sim a condição corpórea de ser no mundo onde o "outro" não é

\footnotetext{
${ }^{4}$ Em contraposição ao pensamento cartesiano de um cogito ergo sum fundado na dicotomia sujeito e objeto onde cabe ao cogito a organização e representação do ser, Merleau-Ponty irá desenvolver o conceito de cogito tácito como uma presença em si anterior à reflexão. Um cogito que é o núcleo de toda a subjetividade e o fundamento de toda percepção onde existe um sujeito no mundo. Esta ideia pode ser melhor compreendida no capitulo "O Cogito" do livro Fenomenologia da Percepção de Merleau-Ponty.
}

R. Inter. Interdisc. INTERthesis, Florianópolis, v.13, n.2, p.19-37, Mai-Ago. 2016 
nem um ser em si nem um objeto:

\begin{abstract}
Sinto meu corpo como potência de algumas condutas e, de certo mundo, sou dado a mim mesmo com um certo poder sobre o mundo; ora, é justamente meu corpo que percebe o corpo de outro, e ele encontra ali como que um prolongamento miraculoso de suas próprias intenções, uma maneira familiar de tratar o mundo; doravante, como as partes de meu corpo em conjunto formam um sistema, o corpo de outrem e o meu são um único, o verso e o reverso de um único fenômeno, e a existência anônima, da qual o meu corpo é a cada momento o rastro, habita esses dois corpos ao mesmo tempo (MERLEAU-PONTY, 1999, p. 470).
\end{abstract}

Deste modo, na construção deste nosso breve texto, decidimos falar em intersubjetividade e não em subjetividade, pois, neste corpo fenomenológico, não podemos considerar os outros na categoria de objetos e nem a nós mesmos quanto objetos dos outros. Neste mundo dos outros, mundo cultural no qual nós nascemos, a subjetividade é intersubjetividade: "Merleau-Ponty compreende que a aquisição de um esquema corporal uno, "total", implica um descentramento de si." (VERISSIMO, 2012, p. 387).

\title{
2 O CONSTRUCIONISMO SOCIAL E A INTERSUBJETIVIDADE
}

Examinemos agora a construção da intersubjetividade na perspectiva do Construcionismo Social que, embora, em modo distinto de Merleau-Ponty com a ideia de corpo fenomênico, também institui uma teoria da intersubjetividade a partir de um questionamento sobre a relação sujeito-objeto.

Esta teoria se refere a um movimento iniciado nos anos oitenta do século $X X$, nas ciências sociais, e que tem alguns de seus principais representantes autores como Gergen, Harré, Pearce e Shotter. Um de seus fundamentos investiga uma visão socio-histórica contrastante com as interpretações provenientes de uma concepção de mundo, a priori negando qualquer forma de essência ou universalidade que busque simplificar a complexidade dos fenômenos sociais (CASTIGLIONI;CORRADINI, 2011). Ou seja, em uma moldura de concepção pósmoderna, o construcionismo social considera o conhecimento uma possibilidade que vai do contexto ao texto e não o contrário. Deste modo, nos parece coerente que, para compreendermos este paradigma, iniciemos por uma leitura de seu contexto/história, contudo, sem construirmos dogmas, pois se trata de um 
pressuposto epistemológico que não busca a verdade nos eventos e sim possíveis construções sociais, narrativas passíveis de novas desconstruções/construções.

\begin{abstract}
A postura antiessencialista presume que as pessoas e o mundo não possuem uma natureza determinada, mas são constituídas nas práticas sociais. Desta forma, não é possível conceber a realidade existindo independentemente do conhecimento que se produz sobre ela antirrealismo -, mas como sendo um emaranhado de versões construídas coletivamente, permitindo uma atitude relativista (MELLO; SILVA; LIMA; DI PAOLO 2007, p.27).
\end{abstract}

Atualmente, o construcionismo social é muito difuso na condição de um parâmetro epistemológico nas análises sociais e psicológicas, mas que, em algum sentido, parece ser vítima de seu próprio sucesso, pois a clareza de seu significado tem sido muito questionável, em base a sua enorme propagação e a galáxia de percursos intelectuais que hoje abarca e que se afirmam construcionistas (SANTAMBROGGIO, 2010).

Pretendemos fazer uma breve consideração inicial sobre a historicidade do construcionismo social e a explicitação de alguns de seus elementos mais comuns que elaboram a ideia de uma intersubjetividade constituinte na experiência humana. A intersubjetividade é tema central nesta teoria, que tem como parâmetros de base, nas diversas vertentes, a busca da compreensão da construção social que está sujeita, por vezes, a banalizar-se se não for melhor elucidada (FELE, 2002).

$\mathrm{Na}$ análise histórica do surgimento do construcionismo social, o psicólogo americano Kenneth Gergen, considerado o 'pai' deste referimento teórico, não considera metodologicamente interessante restringir o início do construcionismo social a um único evento histórico, situando o seu desenvolvimento em um contexto mais amplo:

O surgimento do construcionismo social teria início com a publicação do artigo de Kenneth Gergen "Social psycology as hystory" [...]. Contudo, este mesmo autor questiona a possibilidade de circunscrever desta forma o surgimento do construcionismo. Segundo ele, a história do construcionismo social está inserida no contexto do desenvolvimento da ciência pautada por três críticas ao fazer científico que contribuíram para a construção de uma concepção alternativa ao pressuposto do conhecimento como posse do indivíduo: a crítica social, a ideológica e a retórico-literária (RASERA; JAPUR, 2005, p. 22).

Gergen, situando historicamente o construcionismo social, acrescenta ainda que:

As raízes do construcionismo podem ser rastreadas nos debates de longa data entre as escolas de pensamento empirista e racionalista, o construcionismo busca ultrapassar o dualismo, com o qual ambas as teorias

R. Inter. Interdisc. INTERthesis, Florianópolis, v.13, n.2, p.19-37, Mai-Ago. 2016 
estão comprometidas, e localizar o conhecimento no interior dos processos de intercâmbio social (GERGEN, 2009, p. 300).

É na historicidade de longa duração e não nos fatos históricos singulares que encontramos os motivos de formação das ideias do construcionismo social. No texto citado acima, Gergen nos oferece este elemento de longa duração histórica quando situa suas próprias ideias no contexto dos debates entre empirismo e racionalismo. Em tal perspectiva histórica, não linear e não explicativa dos fatos, é que pretendemos abordar elementos comuns das várias vertentes desta teoria heterogênea, explicitando algumas de suas matrizes de discussões que fizeram parte de seu desenvolvimento na construção de uma outra hermenêutica para a questão da intersubjetividade.

Gergen (2009), preocupando-se em pensar na historicidade e nos elementos comuns deste movimento, contextualiza o surgimento das ideias do construcionismo social na qualidade de uma contraposição entre empiristas e racionalistas, identificando ainda uma outra contraposição importante na formação do pensamento construcionista que é a antinomia exogênico-endogênico:

\begin{abstract}
Estas tradições podem ser amplamente identificadas em termos de orientações ou modelos básicos de conhecimento. Por um lado, pensadores como Locke, Hume, os Mills e vários empiristas lógicos do presente século localizaram a fonte do conhecimento (como representação mental) nos eventos do mundo real. O conhecimento copia (ou deveria idealmente copiar) os contornos do mundo. Esta perspectiva exogênica tende, portanto, a ver o conhecimento como um peão da natureza. O conhecimento apropriado mapeia ou espelha o mundo real como ele é. Em contraste, filósofos como Spinoza, Kant, Nietzsche e vários fenomenólogos tenderam a adotar uma perspectiva endogênica quanto às origens do conhecimento. Neste caso, o conhecimento depende de processos (algumas vezes considerados inatos) endêmicos ao organismo. Diz-se assim que os humanos abrigam tendências inatas a pensar, a categorizar ou processar informação, e que essas tendências (antes do que as características do mundo em si mesmo) são de importância capital na configuração do conhecimento (GERGEN, 2009, p. 307).
\end{abstract}

Outra preocupação de contradição a ser 'superada' por Gergen em sua produção teórica foi a questão da separação entre interno e externo, do biológico e do social. Somos produto do quê? Somos biológicos ou sociais? Nisto encontramos a possibilidade de uma relação com Merleau-Ponty na busca da superação cartesiana:

Uma vez sobrevinda a reflexão, uma vez pronunciado o "eu penso", o pensamento de ser tornou-se de tal modo nosso ser que, se tentamos exprimir o que o precede, nosso esforço desemboca na proposta de um Cogito pré-reflexivo. Mas, que é esse contato de si consigo antes que tenha

R. Inter. Interdisc. INTERthesis, Florianópolis, v.13, n.2, p.19-37, Mai-Ago. 2016 
sido revelado? .[...] Que é, então, esse sentimento de si, que não se possui e que ainda não coincide consigo? Já se disse que roubar a consciência da subjetividade é retirar-Ihe o ser, que um amor inconsciente não é nada, visto que amar é ver alguém, ações, gestos, um rosto, um corpo como amáveis. Mas o cogito antes da reflexão, o sentimento de si sem conhecimento oferecem a mesma dificuldade. (MERLEAU-PONTY, 1980, p. 231).

A contradição entre biológicos ou sociais, para o construcionismo social, tem a sua superação no reconhecimento de que nossa biologia ou forças da natureza não são constituintes de nossas intersubjetividades e sim as relações sociais constituintes.

Os termos com os quais entendemos o mundo são artefatos sociais, produtos historicamente situados de intercâmbios entre as pessoas. Do ponto de vista construcionista, o processo de compreensão não é automaticamente conduzido pelas forças da natureza, mas é o resultado de um empreendimento ativo, cooperativo, de pessoas em relação (GERGEN, 2009, p. 303).

É a vida em sociedade entre os diferentes grupos sociais que irá promover relações e práticas sociais que constituirão os sujeitos. O quadro destas relações em sociedade tem confluência de alguns elementos para o entendimento do desenvolvimento do construcionismo: "na filosofia, como uma reação ao representacionismo, na sociologia do conhecimento, como uma desconstrução da retórica da verdade, e na política, como busca de empowerment de grupos sociais marginalizados" (SPINK; MEDRADO, 2000, p. 23).

Podemos definir o construcionismo social uma epistemologia socio-histórica em conflito com as interpretações de uma visão de mundo a priori, que buscam a naturalização dos fenômenos sociais, através da definição de objetos como algo pronto para observar e descrever. O construcionismo social, historicamente ligado ao pós-estruturalismo e às concepções pós-modernas do mundo, está intrinsecamente associado à autorreflexão de significados e sentidos existentes nos discursos, sejam eles simples ou complexos, científicos ou do cotidiano, em uma realidade fragmentada, difusa e complexa que vai do contexto ao texto e não o contrário.

Nesta teoria, o conhecimento do mundo não é o produto da construção de indução ou de testes empíricos de hipóteses baseadas na observação neutra independente do sujeito do conhecimento e da comunidade da qual faz parte. $O$ construcionismo social é uma mudança de paradigma da epistemologia experiência/experimento para a epistemologia social, onde os processos comuns

R. Inter. Interdisc. INTERthesis, Florianópolis, v.13, n.2, p.19-37, Mai-Ago. 2016 
são prioritários sobre todos os aspectos na construção do conhecimento. É uma visão sociológica do empreendimento científico:

O grau em que uma certa forma de compreensão prevalece ou se sustenta ao longo do tempo não depende fundamentalmente da validade empírica da perspectiva em questão, mas das vicissitudes dos processos sociais (exemplos: comunicação, negociação, conflito e retórica) (GERGEN, 2009, p. 304-305).

Convém enfatizar que o construcionismo social não deve ser confundido com o construtivismo que, embora aceitando a ideia de que são as pessoas que constroem e criam a realidade, se baseia em pressupostos teóricos bem diferentes. Se o construtivismo tem os seus fundamentos baseados nas características biológicas e fisiológicas da percepção individual, colocando o foco nestas, o construcionismo social, diversamente, tem o seu fundamento em uma filosofia de comunidade que concentra a atenção sobre o grupo e a interação entre os seus membros, por meio de processos diários de existência social. Ou seja, ele está centrado nos processos cotidianos, onde as pessoas falam, interagem com os diferentes modos de comunicação, percebem e experimentam, não de acordo com o papel social, que é um termo que ainda remete à ideia de essência, mas de acordo com suas posições no mundo naquele momento. Questão que oferece margem a múltiplas e paradoxais situações diárias, além de incluir a capacidade dinâmica de transformação que as pessoas têm.

É através das atividades simbólicas que os sujeitos descrevem, explicam, reproduzem, reelaboram e entram em contato uns com os outros, num processo de compreensão do mundo em que vivem, por meio de uma atividade considerada um discurso social de conhecimento epistemológico. A prática discursiva conduz ao conjunto das práticas significativas produzidas na materialidade social, a partir da ideia da identidade, em um sistema que funda as forças e contraforças sociais em um processo contínuo. Eis porque os discursos não podem ser considerados apenas representativos, mas sim projetivos e produtores na construção social.

\footnotetext{
A língua é essencialmente uma atividade partilhada, uma vez que todas as atividades humanas são realizadas com base na comunidade. Isto se produz na relação face a face, o outro apresenta-se a mim em uma experiência presente que ambos partilham. O resultado é o constante intercâmbio entre a minha e a sua expressividade (BERGER; LUCKMANN, 1974, p. 42).
}

Este novo paradigma não é uma criação produzida do nada, é sim uma resposta às mudanças nas condições do mundo contemporâneo: "O

R. Inter. Interdisc. INTERthesis, Florianópolis, v.13, n.2, p.19-37, Mai-Ago. 2016 
construcionismo social é uma forma de abordar as circunstâncias na constante mudança em que vivemos" (SCHNITMAN, 1996, p. 182). Desta forma, o construcionismo centra a sua atenção nos processos, defendendo a compreensão humana a partir da condição relacional e diligente às práticas discursivas a base da construção do conhecimento. O mundo interior, neste caso, não é um reflexo dos processos presentes da psique individual, visto que é desenvolvido na ação conjunta em um processo social e linguístico nas contingências através da criatividade das interações humanas, pois essa é resultado e resultante das relações sociais.

Na perspectiva da hermenêutica do construcionismo social, o conhecimento só pode ser entendido quando se considera o contexto no qual ele é produzido; ou seja, o conhecimento é constituído dentro de circunstâncias e em modo coletivo com seus personagens. A realidade dos sujeitos se constitui em uma visão sistêmica e dinâmica onde as dicotomias dentro/fora, sujeito/objeto são abolidas. O ser humano é um ser gregário e deve ser pensado integrado dentro das interações sociais, que são o lugar central da ação e da interpretação do mundo ao seu redor. De fato, é por meio da interação que as pessoas podem transformar seus significados subjetivos em objetivo, dando sentido à realidade. $O$ conhecimento é o resultado das relações intersubjetivas constituintes.

Em suas bases filosóficas, podemos encontrar a leitura de Wittgenstein, As Investigações Filosóficas (1996) que, nas palavras de Gergen, foram "seminais" para o desenvolvimento do movimento construcionista, pois forneceram os pressupostos para o questionamento do uso de conceitos como predicados mentais condicionados por convenções, convidando-nos "a desafiar as bases objetivas do conhecimento" (GERGEN, 2009, p. 302), questionando assim as teorias puramente essencialistas.

A essência, entendida como algo preexistente, predeterminado e predeterminante, não faz parte dos discursos do construcionismo social. O homem essencialmente não é constituído de nada. Isto não quer dizer que os homens, na realidade cotidiana, não tenham em suas vidas pressupostos ou crenças, mas, sim, que estas são versões construídas socialmente e que podem ser revistas e reavaliadas historicamente em sociedade através de nossas práticas. É neste contexto que entra o interesse dos construcionistas sociais pela linguagem na condição de produtora de intersubjetividades.

Esta centralidade dos estudos da linguagem é decorrente do caráter R. Inter. Interdisc. INTERthesis, Florianópolis, v.13, n.2, p.19-37, Mai-Ago. 2016 
estritamente relacional do construcionismo social, pois, através de uma enunciação entre locutor (eu) e interlocutor (o outro), mesmo que este seja fisicamente ausente, cria-se um território social de construção de intersubjetividades.

$\mathrm{Na}$ realidade, toda palavra comporta duas faces. Ela é determinada tanto pelo fato de que procede de alguém, como pelo fato de que se dirige para alguém. Ela constitui justamente o produto da interação do locutor e do ouvinte. Toda palavra serve de expressão a um em relação ao outro. Através da palavra, defino-me em relação ao outro, isto é, em última análise, em relação à coletividade (BAKHTIN, 1995, p. 113).

Bakhtin foi um dos autores que muito influenciou a construção do movimento construcionista, pois para ele não há realidade linguística fora de sua expressão no diálogo. O signo só encontra existência nas relações concretas e pode ser alterado por estas. É a partir desta afirmação que podemos deduzir que a linguagem pode criar novos significantes: "O signo e a situação social em que se insere estão indissoluvelmente ligados. O signo não pode ser separado da situação social sem ver alterada sua natureza semiótica" (BAKHTIN, 1995, p. 62).

Através da linguagem, podemos construir versões diversas de nosso mundo $e$ alterar signos pré-estabelecidos. É por isto que podemos afirmar que o ato de falar é uma ação equivalente a qualquer outra ação material (íNIIGUEZ, 2003). A linguagem em sua condição de ação pode ser entendida como produtora de sentidos para o mundo e campo onde se dará a construção de realidades novas: "A linguagem não é vista mais como barreira entre as pessoas e o mundo, mas uma fronteira de articulação (que nem une e nem separa, mas que constitui)". (MELLO; SILVA; LIMA; DI PAOLO, 2007, p. 28).

Contudo, não é somente a "linguagem", mas sim, a "linguagem agenciada", ou seja, o discurso em suas realizações. É o que Foucault define como "práticas discursivas":

Não podemos confundi-la com a operação expressiva pela qual o indivíduo formula uma ideia, um desejo, uma imagem; nem com a atividade racional que pode ser acionada em um sistema de inferência; nem com a "competência" de um sujeito falante, quando constrói frases gramaticais; é um conjunto de regras anônimas, históricas, sempre determinadas no tempo e no espaço, que definiram, em uma dada época e para uma determinada ação social, econômica, geográfica ou linguística, as condições de exercício da função enunciativa (FOUCAULT, 1987, p. 133).

Foucault nos explicita o que diferencia o discurso da prática discursiva produtora de sentidos, o que corresponde com a perspectiva do movimento construcionista social. Prática discursiva esta que constitui um elemento

R. Inter. Interdisc. INTERthesis, Florianópolis, v.13, n.2, p.19-37, Mai-Ago. 2016 
fundamental para compreendermos as relações de poder instituídas, manifestas nos discursos e em suas produções nas interações sociais. Esta é a duplicidade dos discursos, instituídos e que podem ser também instituintes no processo de promoção do novo.

Discursos não são, como poderia se esperar, um puro e simples entrecruzamento de coisas e palavras. [...] analisando discursos, vemos se desfazerem os laços aparentemente tão fortes das palavras e das coisas e separar um conjunto de regras próprias à prática discursiva. [...] Tarefa que consiste em não mais tratar os discursos como conjuntos de signos (de elementos significantes que remetem a conteúdos ou a representações) mas como práticas que formam sistematicamente os objetos de que falam (FOUCAULT, 1987, p. 64).

As práticas discursivas/narrativas são fundamentais para o movimento do construcionismo social, porque é através delas que se dá o processo de representações sociais:

As pessoas não constroem suas materialidades e compreensões do mundo no vazio, mas na concretude da vida cotidiana, por onde um fluxo contínuo e dinâmico de atos de fala em tensões, conflitos, negociações, solidariedades, contradições, vão configurando sentidos em contínua produção e reprodução (LIMA, 2005, p. 3).

Assim, as narrativas do mundo e de si mesmo entre os homens são fundamentais para a construção das representações sociais, sendo característica básica do movimento construcionista social (GERGEN, 2009). Linguagem é a ação de construção de sentidos e de suas possíveis inter-subjetivações na configuração de fatos estabelecidos. As considerações teóricas realizadas por Gergen expostas aqui nos fazem compreender que a sua ideia de sujeito é o resultado de uma construção social. A ideia de social de Gergen, contudo, é construída na superação da dicotomia exogênica, que observa a atividade psíquica como gerada externamente através dos estímulos recebidos, e, do outro lado, endogênica que observa a atividade psíquica gerada internamente através da mente, do cognitivismo. É na tentativa de Gergen de resolver esta dicotomia que encontraremos a concepção de sujeito do construcionismo social:

Gergen concebe os dois mundos (a mente e o contexto) como produtos de uma mesma realidade socialmente construída no âmbito da comunicação humana, com base em sistemas linguísticos das pessoas em interação: assim, sobre a base de sistemas gerais linguísticos das pessoas e da interação; assim, sobre a base de sistemas gerais de negociação (AMERIO, 2007, p.287). ${ }^{5}$

5 Original: "Gergen concepisce entrambi i mondi (la mente e il contesto) come prodotti di una stessa realtà socialmente costruita nell'ambito della comunicazione umana in base ai sistemi linguistici delle

R. Inter. Interdisc. INTERthesis, Florianópolis, v.13, n.2, p.19-37, Mai-Ago. 2016 
Deste modo, podemos compreender que, para o construcionismo social, a concepção de sujeito é o resultado de uma compreensão interacionista que nos remete à obra de Berger e Luckmann, La realtà sociale come costruzione (1974), diferenciando-se do materialismo histórico que entende o sujeito na condição de um resultado concreto constituído de suas atividades práticas.

Para Gergen, o sujeito se constitui no mundo de negociações discursivas onde o conhecimento não é objetivo e não corresponde a nenhuma "verdade". Assim, o sujeito aqui deve ser compreendido mutável, múltiplo e cheio de contradições, e não deve ser entendido como resultado da vida em sociedade ou realidade primária e sim 0 resultado das negociações discursivas sociais constituintes deste sujeito. Suas premissas são de que o mundo não é um produto do qual prendemos consciência. É um movimento que muda o lócus da racionalidade científica da ciência moderna e grande parte da psicologia que nela se apoia.

O movimento do construcionismo social considera que a origem da realidade social se constrói nas relações humanas, historicamente situadas e constituídas, através da atividade simbólica linguística que constitui o instrumento pelo qual os sujeitos descrevem, explicam, reelaboram, reproduzem e conhecem o mundo no qual vivem. Esta atividade simbólica se conceitua como discurso social, formando a noção de construção social na propriedade de um conhecimento constituído e constituinte que é a base de sua epistemologia na formação do eu/outros, da intersubjetividade.

\section{CONCLUSÃO}

Pudemos considerar, nestas duas perspectivas teóricas longínquas no tempo, em Merleau-Ponty e no construcionismo social, uma preocupação comum na tentativa da superação das dicotomias sujeito-objeto e mente-corpo na construção da intersubjetividade do ser no mundo contrarias a uma ideia de sujeito constituído pelo cogito cartesiano.

persone in interazione: quindi sulla base di generali sistemi linguistici delle persone i interazione: quindi sulla base di generali sistemi di negoziazione sociale". Trad. Marcelo Naputano.

R. Inter. Interdisc. INTERthesis, Florianópolis, v.13, n.2, p.19-37, Mai-Ago. 2016 
Apesar das grandes diferenças de percursos e conclusões explanadas no texto, à guisa de conclusão, é particularmente interessante notarmos a proposição de mudança do lócus na construção da intersubjetividade que se desloca para o "entre", mesmo que em Merleau-Ponty ainda encontremos a necessidade de uma categoria a priori para a instituição deste "entre" como a ideia do corpo fenomênico. Já, no construcionismo social, se propõem que não existe nada a priori e é neste "entre", lugar do encontro com o lócus, que se dá a construção intersubjetiva.

Procuramos ainda, em nosso breve texto, relatarmos a importância que a linguagem tem nestes dois autores o seu ponto central na problematização desta para além de uma compreensão puramente empírica ou racional na construção da relação de sentido entre os sujeitos e o mundo. Para Merleau-Ponty, a lógica da expressão vai passar pela linguagem e pelo corpo, ou seja, a percepção necessária para o estabelecimento da relação entre o sujeito com o instituído para a transcendência de significados em relação ao já estabelecido contexto cultural. Para Gergen, a linguagem se compreende em seu uso pragmático com uma acepção que depende do contexto de seu emprego e os possíveis acordos locais que se transformam sócio-historicamente.

A imediata implicação destas duas possibilidades teóricas é a compreensão de que a sociedade é caraterizada por uma ativa construção intersubjetiva do conhecimento, ou seja, não somos somente o resultado inerte do conhecimento precedente a nossa atuação. Deste modo, a nossa responsabilidade no mundo e da construção de suas representatividades é evidente e nos convida a imputabilidade do que existe. A possibilidade da transformação da "realidade" e a consciência do caráter parcial e ambivalente de nossos conhecimentos e representações culturais deveriam criar em nos um certo relativismo refratário aos discursos de "verdade" e uma abertura ao reconhecimento recíproco das diversidades individuais e coletivas pois, estas mesmas diversidades, promovem novas construções/percepções.

R. Inter. Interdisc. INTERthesis, Florianópolis, v.13, n.2, p.19-37, Mai-Ago. 2016 


\title{
SOME CONSIDERATIONS ON THE INTERSUBJECTIVITY OF MERLEAU-PONTY AND SOCIAL CONSTRUCTIONISM
}

\begin{abstract}
:
The central objective of our text is to understand the construction of Merleau-Ponty's intersubjectivity, and also the subject in relation to the other in their existential constructions. It's also important to do the same reflection on the concept of the intersubjectivity establishment in the Social Constructionism theory, on the possibility of a dialogue, without assuming a moral conclusion on the assumption of a higher valued theory over another. To do so, we begin with some brief remarks about the affections and historical enemies of philosophy and psychology, to later introduce Merleau-Ponty's central point of view and Social Constructionism, thus developing possible intersubjectivity meanings. It is interesting to note that, despite the distance in time and in the theoretical construction between Merleau-Ponty and Social Constructionism, we can see a similarity in finding a solution to the subject-object problem by transcending the intersubjectivity considerations polarization, even with divergent proposals.
\end{abstract}

Keywords: Intersubjectivity. Merleau-Ponty. Social Constructionism

\section{LA INTERSUBJETIVIDAD EN MERLEAU-PONTY Y EL CONSTRUCCIONISMO SOCIAL, ALGUNAS CONSIDERACIONES}

\section{Resumen:}

El objetivo principal de nuestro texto es entender la construcción de la intersubjetividad en Merleau-Ponty, del sujeto en relación con el otro en sus construcciones existenciales y hacer la misma reflexión sobre el concepto de intersubjetividad establecido en la teoría del Construccionismo Social, con la posibilidad de un diálogo, sin la presuposición de una conclusión de carácter moral de asignación de un valor más alto para una teoría sobre otra. Para ello, partimos de algunas breves consideraciones sobre los proximidades y distanciamientos históricos entre filosofía y psicología para después delinear mejor nuestro punto central sobre Merleau-Ponty y el Construccionismo Social, desarrollando los posibles significados de inter-subjetividad en ellos. Es interesante notar que a pesar de la distancia en el tiempo y la construcción teórica de Merleau-Ponty y el Construccionismo Social, podemos ver una similitud en la búsqueda de una solución al problema sujeto-objeto que trasciende esta polarización en las consideraciones sobre la inter-subjetividad aunque con diferentes propuestas.

Palabras clave: Intersubjetividad. Merleau-Ponty. Construccionismo Social. 


\section{REFERÊNCIAS}

AMERIO, P. Fondamenti di psicologia sociale. Bologna, II Mulino, 2007.

BAKHTIN, M. Marxismo e filosofia da linguagem. São Paulo, Hucitec, 1995.

BERGER, P; LUCKMANN, T. A construção social da realidade. Bologna: II Mulino, 1974.

CASTIGLIONI, M.; CORRADINI, A. Modelli epistemologici in psicologia. Dalla psicoanalisi al costruzionismo. Roma: Carocci, 2011.

COELHO JÚNIOR, N.; CARMO, P. Merleau-Ponty: filosofia como corpo e existência. São Paulo: Escuta, 1991.

FELE, G. Etnometodologia, Roma: Carocci, 2002.

FIGUEIREDO, L. C. M.; DE SANTI, P. L. R. Psicologia: Uma (nova) introdução. São Paulo: EDUC, 2004.

FOUCAULT, M. Arqueologia do saber. Rio de Janeiro: Forense Universitária, 1987.

FOULQUIÉ, P. A psicologia contemporânea. São Paulo: Companhia Editora Nacional, 1965.

GERGEN, K. J. O movimento do construcionismo social na psicologia moderna. Revista Internacional Interdisciplinar INTERthesis, Florianópolis, v.6 (1), 2009, p. 299-325. Disponível em:

$<$ https://periodicos.ufsc.br/index.php/interthesis/article/view/18071384.2009v6n1p299>. Acesso em: 25 jul. 2014.

ÍNIIGUEZ, L. La psicología social en la encrucijada postcons-truccionista: historicidad, subjetividad, performatividad, acción. In: XII Encontro Nacional da ABRAPSO, Porto Alegre, RS. 2003.

LIMA, A. B. Algumas reflexões para uma práxis crítica em Psicologia Social. (texto R. Inter. Interdisc. INTERthesis, Florianópolis, v.13, n.2, p.19-37, Mai-Ago. 2016 
não publicado). IV Encontro do Departamento de Psicologia Social e Institucional e VII Mostra de Produção Científica. Londrina: Universidade Estadual de Londrina, 2005, p. 3-10.

MELLO, R.P.; SILVA, A.A.; LIMA, M.L.C.; DI PAOLO, A.F. Construcionismo, práticas discursivas e possibilidades de pesquisa. In: Psicologia \& Sociedade, 19 (3), 2007, p. 26-32. Disponível em: <http://www.repositorio.ufc.br/handle/riufc/2775>. Acesso em: 01 ago. 2014.

MERLEAU-PONTY. M. Fenomenologia da percepção (2a ed.). São Paulo: Martins Fontes, 1999.

MERLEAU-PONTY. M. O olho e o espírito. São Paulo: Cosac \& Naify, 2004.

MERLEAU-PONTY. M. Senso e non senso, Milano: II Saggiatore, 1996.

MERLEAU-PONTY. M. Textos escolhidos. Coleção "Os Pensadores". São Paulo: Abril Cultural,"), 1980.

MERLEAU-PONTY. M. L'institution. La passivité. Notes de cours au Collège de France (1954-1955). Tours: Belin, 2003.

RASERA, E. F.; JAPUR, M. Os sentidos da construção social: o convite construcionista para a Psicologia. Paidéia - Cadernos de Psicologia e Educação (online), Ribeirão Preto, v. 15 (30), 2005. Disponível em: http://sites.ffclrp.usp.br/paideia/artigos/30/04.htm. Acesso em 24 jul. 2014.

SANTAMBROGIO, A. Costruzionismo e scienze sociali. Perugia: Morlacchi, 2010.

SANTOS, B. de S. Um discurso sobre as ciências na transição para uma ciência pós-moderna. Estudos Avançados, vol.2, n.2, 1998, p. 46-71. Disponível em: http://www.scielo.br/scielo.php?script=sci arttext\&pid=S0103-40141988000200007. Acesso em: 15 jul. 2014.

SCHNITMAN, D (org.). Novos paradigmas, cultura e subjetividade. Porto Alegre, Artes Médicas. 1996.

SPINK, M. J. P.; MEDRADO, B. Produção de sentidos no cotidiano: uma abordagem teórico-metodológica para análise das práticas discursivas. São Paulo: Cortez, 2000.VERISSIMO, D. S. No limiar do mundo visível: a noção de esquema corporal

R. Inter. Interdisc. INTERthesis, Florianópolis, v.13, n.2, p.19-37, Mai-Ago. 2016 
nos cursos de Merleau-Ponty na Sorbonne. PSICOLOGIA USP, 23(2), São Paulo, 2012, p. 367-393. Disponível em:

$<$ http://www.scielo.br/scielo.php?script=sci arttext\&pid=S0103-

65642012000200007>. Acesso em: 25 jul.2014.

WITTGENSTEIN, L. Investigações filosóficas, São Paulo: Vozes, 1996.

\section{Artigo}

Recebido em 13 de Janeiro de 2016

Aceito em 08 de Maio de 2016

R. Inter. Interdisc. INTERthesis, Florianópolis, v.13, n.2, p.19-37, Mai-Ago. 2016 